\title{
Effective forms of market orientation across the business cycle: A longitudinal analysis of business-to-business firms
}

\author{
Johanna Frösén a,*, Matti Jaakkola ${ }^{\text {b }}$, Iya Churakova a , Henrikki Tikkanen ${ }^{\text {c,d }}$ \\ a St. Petersburg State University, Graduate School of Management, Volkhovskiy pereulok 3, 199004 St. Petersburg, Russia \\ b Aston Business School, Aston University, Aston Triangle, B4 7ET Birmingham, United Kingdom \\ c Aalto University School of Business, PO Box 21230, FI-00076 Aalto, Finland \\ d Stockholm Business School, Stockholm University, Kräftriket 3A, S-114 19 Stockholm, Sweden
}

\section{A R T I C L E I N F O}

\section{Article history:}

Received 15 February 2014

Received in revised form 27 March 2015

Accepted 2 April 2015

Available online $\mathrm{xxxx}$

\section{Keywords:}

Market orientation

Firm performance

Business cycle

Industry sector

Configuration

\begin{abstract}
A B S T R A C T
Macroeconomic developments, such as the business cycle, have a remarkable influence on firms and their performance. In business-to-business (B-to-B) markets characterized by a strong emphasis on long-term customer relationships, market orientation (MO) provides a particularly important safeguard for firms against fluctuating market forces. Using panel data from an economic upturn and downturn, we examine the effectiveness of different forms of MO (i.e., customer orientation, competitor orientation, interfunctional coordination, and their combinations) on firm performance in B-to-B firms. Our findings suggest that the impact of MO increases especially during a downturn, with interfunctional coordination clearly boosting firm performance and, conversely, competitor orientation becoming even detrimental. The findings further indicate that both the role of $\mathrm{MO}$ and its most effective forms vary across industry sectors, MO having a particularly strong impact on performance among B-to-B service firms. The findings of our study provide guidelines for executives to better manage performance across the business cycle and tailor their investments in MO more effectively, according to the firm's specific industry sector.
\end{abstract}

(C) 2015 Elsevier Inc. All rights reserved.

\section{Introduction}

Macroeconomic developments, such as the business cycle, have a remarkable influence on firms and their performance, thus posing a significant challenge for management (e.g., Deleersnyder, Dekimpe, Sarvary, \& Parker, 2004; Naidoo, 2010). On the one hand, during economic downturns customers are likely to cut spending and become less loyal, which results in intensified competition and decreasing firm profitability (Grewal \& Tansuhaj, 2001; Pearce \& Michael, 2006). This is likely to lead to challenges particularly for firms operating in business-to-business (Bto-B) markets, since these firms are characterized by long-term customer relationships and a relatively low number of actors in the marketplace (e.g., Liao, Chang, Wu, \& Katrichis, 2011). On the other hand, during periods of economic upturn, firms often face challenges in (re)allocating resources to meet growing demand, satisfying emerging customer needs, and identifying new opportunities for creating value (e.g., Christensen \& Bower, 1996; Slater \& Narver, 1994).

While the effective use of marketing-related resources across the business cycle is a crucial issue for many firms (e.g., Andersson \&

\footnotetext{
* Corresponding author. Tel.: + 79213971829.

E-mail addresses: froesen@gsom.pu.ru (J. Frösén), m.jaakkola@aston.ac.uk (M. Jaakkola), churakova@gsom.pu.ru (I. Churakova), henrikki.tikkanen@aalto.fi (H. Tikkanen).
}

Mattsson, 2010; Srinivasan, Rangaswamy, \& Lilien, 2005), extant conceptual and empirical studies on the topic remain scant. The majority of prior studies concentrate on aggregate-level marketing investments, proposing that these should be continued even in the face of tightening resources during an economic downturn (e.g., Srinivasan, Lilien, \& Sridhar, 2011; Srinivasan et al., 2005). Another line of research (e.g., Deleersnyder, Dekimpe, Steenkamp, \& Leeflang, 2009; Steenkamp \& Fang, 2011) focuses mainly on the effectiveness of distinct marketing activities, such as advertising, across the business cycle.

From the resource perspective, existing studies emphasize that companies should be flexible in adjusting their marketing strategies and tactics to the changing economic environment during all phases of the business cycle (e.g., Quelch \& Jocz, 2009). This general finding lays the groundwork for the present study, as we argue that organizationlevel market orientation (MO) reflects such alertness and flexibility to respond to changes in a firm's business environment, whether these relate to shifting customer needs or competitors' actions (Narver \& Slater, 1990). We therefore suggest that MO plays an important role in creating customer value in B-to-B companies during economic upturns, and serves as an effective shelter against declining economic conditions and diminishing profits during times of intense competition and uncertain demand, which are hallmarks of economic crises (Alajoutsijärvi, Klint, \& Tikkanen, 2001; Grewal \& Tansuhaj, 2001). 
Although MO is often treated as a unidimensional construct (e.g., Grewal \& Tansuhaj, 2001; Hult \& Ketchen, 2001; Jaworski \& Kohli, 1993), recent empirical studies (e.g., De Luca, Verona, \& Vicari, 2010; Noble, Sinha, \& Kumar, 2002) propose that the performance implications of its dimensions (Narver \& Slater, 1990) differ in magnitude. Furthermore, recent studies evidence the economic environment in which firms operate to determine the performance outcomes of individual MO dimensions, and thus, the effective forms of MO (cf. Smirnova, Naudé, Henneberg, Mouzas, \& Kouchtch, 2011). In other words, the performance implications of the distinct MO dimensions as well as their combinations may also vary in magnitude across the business cycle (cf. Andersson \& Mattsson, 2010).

This study aims at identifying the most effective forms of MO for B-to-B firms operating in different industries and economic environments. Drawing on the above discussion, we examine the performance implications of distinct forms of MO, defined as different combinations of customer orientation, competitor orientation, and interfunctional coordination, 1) over the business cycle, and 2) among different types of B-to-B firms. Disaggregating MO into three dimensions in our longitudinal analysis enables us to address the relative importance of its different forms, especially in a firm's transition from an economic upturn to a downturn. Finally, we identify a number of forms of MO consistently associated with high performance. These forms are specific to distinct industry sectors, and thus, can be used as benchmarks for firms operating in specific B-to-B markets.

The remainder of this article is organized as follows. First, we provide an overview of the current literature on the dimensions of $\mathrm{MO}$ and firm performance, and develop hypotheses for the role the business cycle may play in these relationships. We also discuss the role of industry sector as a contingency factor. Second, we discuss our research methodology in collecting and analyzing the data. Third, we present the findings of our empirical analyses, and finally, conclude by discussing the study's contributions, managerial implications, limitations, and avenues for future research.

\section{Theoretical background and hypothesis development}

\subsection{On the importance of considering distinct forms of $M O$}

As an organizational culture concerned with enhancing firm performance by creating superior value for customers, MO reflects how a firm relates to its markets (Narver \& Slater, 1990). The role of MO is often emphasized in B-to-B markets due to the importance of long-term customer relationships and the relatively small number of actors in the market, which both promote firms' dependence on individual customer relationships (e.g., Liao et al., 2011). Therefore, gaining a deep understanding of a firm's present and future customers as well as its competitors' strategies and offerings is considered an especially important determinant of firm performance (e.g., Mattsson, 2009; Tuominen, Rajala, \& Möller, 2004).

To date, most empirical studies on the MO-performance relationship concentrate on the aggregate level MO (e.g., Grewal \& Tansuhaj, 2001; Hult \& Ketchen, 2001; Jaworski \& Kohli, 1993). However, in this study, we posit that considering MO as an aggregate-level concept is somewhat misleading since the distinct MO dimensions are related to different strategic foci (Porter, 1980). While customer orientation relates mostly to enhancing profits by increasing revenue through superior customer value, interfunctional coordination, through enhanced effectiveness and efficiency, also contributes to reducing cost. Furthermore, strong competitor orientation enables a firm to closely follow and even imitate competitors' competitive actions or, alternatively, to differentiate its offering. Since firms may adopt strategies with diverse or multiple foci, it is useful to treat MO analytically as three distinct dimensions and their combinations.

\subsection{Forms of $M O$, firm performance, and the business cycle}

The general relationship between MO and firm performance varies depending on the economic environment (Grewal \& Tansuhaj, 2001). In B-to-B markets, where demand is derived from the demand for further refined offerings in consumer markets, major shifts in the economic environment are even more likely to cause variation in the performance implications of a firm's marketing (cf. Alajoutsijärvi et al., 2001), including its adoption of MO. Due to the different strategic foci required from firms to cope with economic upturns and downturns, the business cycle is also likely to affect the performance outcomes of the different forms of MO.

Customer orientation refers to a shared set of beliefs that puts the customer's interest first (Deshpandé, Farley, \& Webster, 1993). It also incorporates constantly seeking to uncover both expressed and latent customer needs (Narver, Slater, \& MacLachlan, 2004). Since customer needs change over time, it is important for companies to constantly scan changes in customer preferences, which helps manage demand uncertainty throughout the business cycle (Grewal \& Tansuhaj, 2001; Pearce \& Michael, 1997).

In this study, we posit that during economic upturns characterized by less intense competition, firms are typically able to get better margins from their customers because of the customers' reduced price sensitivity compared to downturns (cf. Gordon, Goldfarb, \& Yang, 2013; Van Heerde, Gijsenberg, Dekimpe, \& Steenkamp, 2013). Therefore, in these environments, investing in customer value creation is also likely to generate higher profits. On the other hand, during an economic downturn, the firm's focus shifts from understanding expressed and latent customer needs to prioritizing short-term sales and survival (Wilkinson, 2010). This is because customers facing increased economic uncertainty are likely to postpone purchases and become more price sensitive, hence diminishing the value of factors such as customer loyalty or long-term customer satisfaction (cf. Rust \& Zahorik, 1993). Based on this logic, we hypothesize that:

H1. The positive relationship between customer orientation and firm performance is weaker during an economic downturn than during an upturn.

Competitor orientation denotes a culture that promotes gaining and maintaining a deep understanding of competitors' strengths, weaknesses, capabilities, and strategies (Narver \& Slater, 1990). During both prosperous and tight economic times, a firm that constantly scans its industry and competitive environment is better able to detect relevant business opportunities (Naidoo, 2010; Pearce \& Michael, 1997), and to use this understanding in differentiating its offerings (Grinstein, 2008). Roberts (2003), for instance, argues that firms whose offerings customers perceive as better value for money than the offerings of their rivals, are more profitable during times of recession and also grow faster once recovery starts.

Competition generally intensifies during an economic downturn (Jaworski \& Kohli, 1993), stressing the need for a firm to sense and react to competitors' actions rapidly. Furthermore, increased market uncertainty and the scarcity of marketing resources lead firms to seek legitimacy and reduced risk for their operations by focusing on offerings and procedures that have already been proved successful by competition (De Luca et al., 2010; Srinivasan et al., 2005; cf. Quelch \& Jocz, 2009). Therefore, we hypothesize that:

H2. The positive relationship between competitor orientation and firm performance is stronger during an economic downturn than during an upturn.

Finally, interfunctional coordination relates to a firm's coordinated efforts and commitment to creating superior value for customers (Narver \& Slater, 1990). Diminishing gaps between different business functions can lead to increased synergies and better operational efficiency and effectiveness (Rollins, Nickell, \& Ennis, 2014; Ruekert \& Walker, 1987). 
For instance, firms are generally more effective in developing innovations when they share goals and exhibit greater levels of integration between marketing and R\&D (De Luca et al., 2010; Im \& Workman, 2004). Interfunctional coordination is particularly crucial in B-to-B relationships, where a broader interface between the firm and its customers increases the customers' points of contact with the firm across its different functions (e.g., Grönroos, 1994; Lai, Pai, Yang, \& Lin, 2009).

Due to increasing competition over scarce resources during an economic downturn, firms need to pay attention specifically to the efficient allocation and sharing of these resources. Tight integration between business functions reduces the risk of delayed and suboptimal decision making (De Luca et al., 2010) when fast changes in the marketplace require more strategic agility from the firm (cf. Doz \& Kosonen, 2010) and create a particular need for disseminating information and responding to this information "in concert". This leads to our final hypothesis:

H3. The positive relationship between interfunctional coordination and firm performance is stronger during an economic downturn than during an upturn.

\subsection{Industry sector as a contingency factor}

The effects of business cycle on different businesses and their performance vary. While, for instance, manufacturing of durable goods is a highly cyclical industry, demand for services is more stable, partly because services cannot be stored (Pearce \& Michael, 2006). The MO-firm performance relationship might also vary between industry sectors. Kirca, Jayachandran, and Bearden (2005), for example, found that the relationship is more positive in manufacturing firms than in service firms. Furthermore, the firm's type of offering has been shown to affect the form of $M O$ the firm is likely to adopt. For instance, service-focused firms have been found to place specific focus on customer orientation (Zhou, Brown, \& Dev, 2009). At the same time, customer orientation has been shown to have a higher impact on customer satisfaction for products than for services (Nilsson, Johnson, \& Gustafsson, 2001). These findings suggest that the industry in which a firm operates affects both the form of MO the firm adopts and its performance implications.

A possible explanation for the industry-specificity of MO adoption and its performance implications stems from the so-called Red Queen effect (e.g., Barnett, Greve, \& Park, 1994); in order to yield performance gains, a firm's MO needs to be at a higher level than that of its competitors belonging to the same strategic group (cf. Chen, Su, \& Tsai, 2007). Therefore, the general emphasis placed on customer orientation, competitor orientation, and/or interfunctional coordination in a specific industry may also influence the effectiveness of the different forms of MO within that industry context (cf. Kumar, Jones, Venkatesan, \& Leone, 2011). In sum, we assume the performance implications of MO over the changing business cycle to also vary across firms in different industry sectors.

\section{Methodology}

\subsection{Data}

This study is based on two data sets collected in Finland in spring 2008 and in spring 2010. Year 2008 still represents economic growth in Finland (change in GDP from previous year 3.2\% ${ }^{1}$ ), whereas by 2010 the great financial crisis (e.g., Rollins et al., 2014) had also hit the Finnish economy (GDP 3.7\% less than in 2008). Fig. 1 illustrates the quarterly development of Finnish GDP between 2007 and 2011, evidencing that GDP started declining in the third quartile of 2008, plunged rapidly, and started

\footnotetext{
1 Statistics Finland (2012): http://www.stat.fi/til/vtp/2012/vtp_2012_2013-07-11_tau_ 001_en.html, accessed 15 August 2013.
}

recovering slowly only after the first quartile of 2010 (Statistics Finland, $2013^{2}$ ). Our data thus captures two significantly different phases of the business cycle: an upturn and a downturn.

Although the impact of the crisis hit Finnish GDP only in late 2008, the decline in both industry ${ }^{3}$ and consumer ${ }^{4}$ sentiment indicators reacted to global market developments at a faster rate, and these predicted the impacts of the great financial crisis even before it reached the local market. Thus, changes in economic outlook may have affected firms' investments in the distinct MO dimensions and, therefore, the forms of MO firms adopted. Nevertheless, MO as an organizational culture (Narver \& Slater, 1990) is expected to change relatively slowly. Furthermore, in the present study, we are not concentrating on the level of firms' MO or their investments therein, but rather on the relationship between the distinct forms of MO and firm performance. From this perspective, the varying level of investments is not considered to significantly affect the relative contribution of $\mathrm{MO}$ - and the forms thereof - to firm performance, which is the focus of the present study.

Data were collected through a Web-based questionnaire addressed to top management teams in all Finnish firms with more than five employees. In this article, we focus on three major, largely B-to-B-oriented industries in Finland: manufacturing, information and communications, and professional services, which together account for up to $74 \%$ of the total annual turnover of Finnish firms. ${ }^{5}$ The Finnish economy has traditionally relied heavily on its industrial sector (e.g., Jaakkola, Möller, Parvinen, Evanschitzky, \& Mühlbacher, 2010), especially on the forest and metal industries (e.g., Hjerppe \& Jalava, 2006) and the ICT sector (e.g., Asplund \& Maliranta, 2006). Findings from the Wholesale and retail trade industry, representing a classical business-to-consumer service industry, are presented as a point of comparison.

The pilot version of the questionnaire was tested with 34 managing directors. After a few minor corrections and changes in wording, the pre-tested survey was sent to the respondents. The sampling frame was derived from a commercial database provided by MicroMedia. In 2008 , the survey yielded a firm-level response rate of $16 \%$ (11\% in 2010), with 525 usable responses (812 in 2010). For the longitudinal analysis, only firms for which data were acquired from both years could be included, resulting in a panel data of 140 firms. Table 1 provides key information on the industry structure of the panel data as well as the distribution of the sample firms in terms of their size.

We tested non-response bias through an analysis of the mean scores on the survey items for early versus late respondents (Armstrong \& Overton, 1977). T-tests at the 0.05 level revealed no significant differences.

\subsection{Measures}

The classic MKTOR-scale, including the dimensions of customer orientation, competitor orientation, and interfunctional coordination (Narver \& Slater, 1990), was used to measure MO. For each dimension, a summated composite value was calculated. Firm performance was captured by the firm's objective return on investment (ROI), acquired from a commercial database, Voittoplus, which gathers economic indices for Finnish firms from the firms' annual statements. Before conducting the final analysis, the ROI of each firm was corrected by the industry median, acquired from the same database, to control for natural variation in performance across industry sectors (Statistics Finland, $2012^{6}$; cf. Powell, 1996). ROI was chosen as a key measure of

\footnotetext{
2 Statistics Finland (2013): http://www.stat.fi/til/ntp/2013/02/ntp_2013_02_2013-0905 tie_001_en.html, accessed 15 September 2013.

${ }^{3}$ Confederation of Finnish Industries (2010): http://pda.ek.fi/www/fi/tutkimukset_ julkaisut/2010/5_touko/Luottamusindikaattori1005.pdf, accessed 15 April 2014

4 Statistics Finland (2014): http://www.stat.fi/til/kbar/2014/03/kbar_2014_03_201403-27_tie_001_en.html, accessed 15 April 2014.

5 Statistics Finland (2012): http://pxweb2.stat.fi/database/StatFin/yri/syr/010_yr_ tol08/010_yr_tol08_fi.asp, accessed 23 April 2014

${ }^{6}$ Statistics Finland (2012): http://www.stat.fi/artikkelit/2012/art_2012-10-22_001. html? $\mathrm{s}=0$, accessed 15 August 2013.
} 


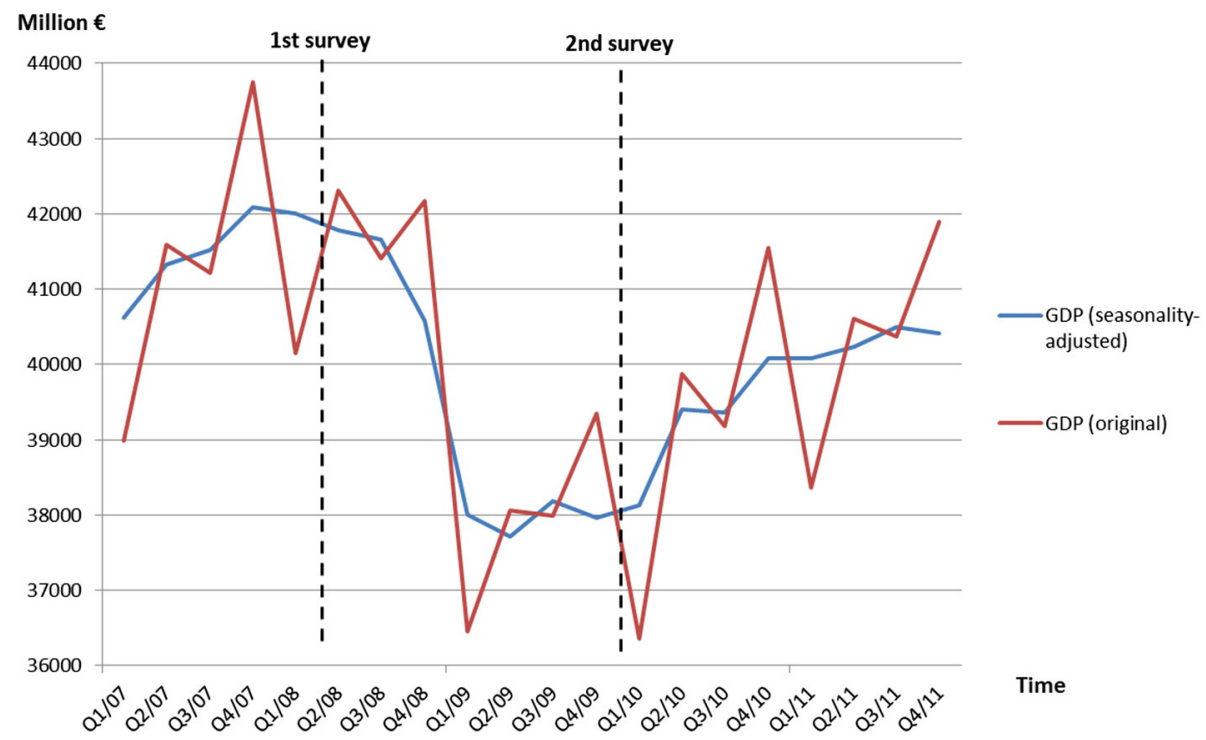

Fig. 1. Quarterly development of GDP in Finland between 2007 and 2011.

performance because it directly addresses firm profitability, which is likely to be affected the most by intense competition and lowered prices characteristic of economic downturns. Furthermore, ROI as a short-term performance measure adroitly captures the impact of a firm's reactions to the changing business cycle. Objective measures were chosen 1) to show the natural variation in the resulting variable, and, therefore, to be able to evaluate more precisely the relationship between the forms of MO and performance, and 2) to avoid common method bias (cf. Im \& Workman, 2004). The number of employees, a measure of firm size, was used as a control variable in all statistical models. Table 2 shows the key summary statistics of the data.

Following Harman's one-factor test for common method bias, an unrotated principal component analysis of the MO items was conducted. This analysis identifies two factors with eigenvalues greater than one that together explain 54\% of the total variance (including the theoretical third factor, with an eigenvalue of slightly below one, increases the total variance explained to $62 \%$ ), with no single factor accounting for more than $50 \%$ of the variance. Thus, common method bias does not seem to threaten the validity of our findings (Podsakoff \& Organ, 1986). Also, as our outcome variables are derived from an external, objective source, the potential for common method bias is reduced (cf. Im \& Workman, 2004).

Confirmatory factor analysis using LISREL (Jöreskog \& Sörbom, 1993) was then used to test for measurement invariance (Horn \& McArdle, 1992; Steenkamp \& Baumgartner, 1998), with results presented in Table 3.

To ensure configural invariance (Horn \& McArdle, 1992), all items with a factor loading below 0.50 on either data set were removed from the analysis. The data also reflect metric invariance (Rock, Werts, \& Flaugher, 1978) and factor variance invariance (Steenkamp \& Baumgartner, 1998). Even if we do not find full support for scalar invariance needed for mean comparison, as the focus of this study is not on comparing the means but on studying the performance relationships, this is not considered a problem. Regarding the goodness-of-fit indices, the measures of NNFI, CFI, and RMSEA suggest a sufficient fit (Lance, Butts, \& Michels, 2006; MacCallum, Browne, \& Sugawara, 1996).

\subsection{Analytical approaches}

We employ two complementary analytical techniques in this study: longitudinal regression analysis and fuzzy set Qualitative Comparative
Analysis (fsQCA). Taken together, our analyses provide a comprehensive and detailed perspective of the changing role of $\mathrm{MO}$ and its distinct dimensions over the business cycle.

\subsubsection{Longitudinal regression analysis}

Our regression models are estimated using mixed effects modeling. For each time period $t$, and for each firm $f$, we model firm performance (Perf) as a linear function of the three dimensions of MO, which are customer orientation (CUO), competitor orientation (COO), and interfunctional coordination (IFC). We simultaneously control for firm size in terms of the number of employees $(N E)$. Including fixed effects in the model allows us to control for the average differences across individual firms and to reduce the threat of omitted variable bias. Fixed effects included in the model keep individual effects constant:

$\operatorname{Per} f_{f t}=\beta_{0 t}+\beta_{1 t} C U O_{f t}+\beta_{2 t} C O O_{f t}+\beta_{3 t} I F C_{f t}+\beta_{4 t} N E_{f t}+\gamma_{f} D^{\prime}+v_{t}$

where $D^{\prime}$ represents a set of dummy variables for individual firms and $v_{t}$ represents model residuals. The firm-specific intercepts in Eq. (1) are related to an unobserved variable that varies across firms but is constant across time periods.

Random effects are included in the models to help us control for unobserved heterogeneity, assuming this heterogeneity is constant over time and correlates with the independent variables. The random effects model can be formulated as:

$\operatorname{Perf}_{f t}=\beta_{0 t}+\beta_{1 t} C U O_{f t}+\beta_{2 t} C O O_{f t}+\beta_{3 t} I F C_{f t}+\beta_{4 t} N E_{f t}+w_{f}+\varepsilon_{f t}$

where $w_{f}$ is the firm-specific random effect and $\varepsilon_{f t}$ stands for errors.

Table 1

Sample distribution.

\begin{tabular}{lllc}
\hline Industry sector & $\%$ & $\begin{array}{l}\text { Size } \\
\text { (number of employees) }\end{array}$ & $\%$ \\
\hline Manufacturing & 33 & Small (less than 50) & 39 \\
Information and communication & 14 & Medium sized (51-250) & 33 \\
Professional, scientific, and technical activities & 17 & Large (more than 250) & 28 \\
Wholesale and retail trade & 14 & & \\
Other & 21 & & \\
\hline
\end{tabular}


Table 2

Summary statistics of the data.

\begin{tabular}{|c|c|c|c|c|c|c|c|}
\hline \multirow[t]{2}{*}{ Variable } & \multicolumn{3}{|l|}{2008} & \multicolumn{3}{|l|}{2010} & \multirow[t]{2}{*}{ Difference } \\
\hline & Mean & SD & Cronbach's alpha & Mean & SD & Cronbach's alpha & \\
\hline ROI (objective) & 14.52 & 34.05 & - & 40.73 & 263.42 & - & 26.21 \\
\hline Customer orientation & 5.36 & 0.90 & 0.81 & 5.54 & 0.82 & 0.80 & $0.18^{*}$ \\
\hline Competition orientation & 4.86 & 0.97 & 0.65 & 4.96 & 1.01 & 0.61 & 0.10 \\
\hline Interfunctional coordination & 5.06 & 1.06 & 0.78 & 5.27 & 0.97 & 0.71 & $0.22^{*}$ \\
\hline Size (no. of employees) & 5.19 & 1.98 & - & 5.18 & 1.94 & - & -0.01 \\
\hline
\end{tabular}

$* \mathrm{p} \leq 0.10$.

$* * \mathrm{p} \leq 0.05$.

$* * * \mathrm{p} \leq 0.01$.

As our data set represents firms from different industry sectors, additional cross-level interactions and random coefficients are needed to take into account industry-level variation. To incorporate this possible variation in our analysis, we include dummies for industry sector in our final mixed effects model, stated as:

$\operatorname{Perf}_{f t}=w_{f}+\lambda_{t}+\mathbf{x}_{\mathbf{f t}}^{\prime} \boldsymbol{\beta}+\mathbf{I}+\varepsilon_{f t}$

where $\lambda_{t}$ is a random time component, $\mathbf{x}_{\mathbf{f t}}{ }^{\prime}$ is the matrix of explanatory variables, $\boldsymbol{\beta}$ represents fixed effects, and $\mathbf{I}$ is a matrix of industry dummies.

\subsubsection{Fuzzy set Qualitative Comparative Analysis}

The regression analyses provide valuable insights into how firms, on average, benefit from MO and its distinct dimensions in coping with economic fluctuations. However, as the successful "recipes" for handling market uncertainty under varying economic conditions are firm specific (Rollins et al., 2014; cf. Eisenhardt \& Martin, 2000), the effective forms of MO are also likely to vary from firm to firm. To gain further insight into the complex relationship between $\mathrm{MO}$ and firm performance across different industries and phases of the business cycle, we apply fsQCA, a novel method recently adopted in management studies (Fiss, 2007; Ragin, 2008). fsQCA was selected as the method of analysis as it specifically allows for equifinality (i.e., multiple paths leading to the same outcome) in configurations (e.g., Doty, Glick, \& Huber, 1993). Furthermore, compared to regression, fsQCA enables revealing indirect, combinatory relationships between causal conditions (such as the dimensions of MO) and the outcome (here firm performance) (Fiss, 2007). The analysis is based on a truth table algorithm (Ragin, 2008) provided by the fs/QCA 2.0 software.

The direct method (Ragin, 2008) was used to calibrate the fuzzy-set memberships for each variable. For the distinct MO dimensions, customer orientation, competitor orientation, and interfunctional coordination, initially measured by a seven-point Likert scale, the threshold for full membership in high orientation (fuzzy score of 0.95) was defined as a ratio of seven, the crossover point (fuzzy score of 0.50) as a ratio of four, and the threshold for exclusion (fuzzy score of 0.05 ) as a ratio of one (see Frambach, Fiss, \& Ingenbleek, 2010). For firm size, in line with the definitions used by Statistics Finland, the threshold for

Table 3

Assessment of invariance.

\begin{tabular}{lllllllll}
\hline 2008 vs. 2010 & $\chi^{2}$ & $d f$ & $\Delta \chi^{2}$ & $\Delta d f$ & RMSEA & CAIC & NNFI & CFI \\
\hline Configural invariance & 565.86 & 105 & - & - & 0.086 & 1171.16 & 0.95 & 0.96 \\
Metric invariance & 578.06 & 114 & 12.20 & 9 & 0.083 & 1110.73 & 0.96 & 0.96 \\
$\begin{array}{l}\text { Factor variance } \\
\quad \text { invariance }\end{array}$ & 578.25 & 117 & 0.19 & 3 & 0.082 & 1086.71 & 0.96 & 0.96 \\
$\quad$ Scalar invariance & 619.89 & 126 & $41.83^{*}$ & 12 & 0.082 & 1055.71 & 0.96 & 0.96 \\
\hline$* \quad \mathrm{p}<0.05$ & & & & & & & &
\end{tabular}

"large firms" was set at 250 employees, and for "small firms" at less than 50 employees. The industry sector(s) associated with each configuration were marked using crisp set calibration, assigning each industry sector a value of 1 or 0 .

As what constitutes a "high" or "low" performance, especially in terms of ROI, differs across different industry sectors, the outcome variable was calibrated against industry-specific thresholds. The threshold for full membership in high firm performance (fuzzy score of 0.95) was defined as a ratio of the threshold value for the national third quartile among all firms within the industry of interest, the crossover point (fuzzy score of 0.50 ) as a ratio of the median, and the threshold for exclusion (fuzzy score of 0.05 ) as a ratio of the first quartile.

In this study, only configurations with observed empirical instances were included in the analysis. Following recommendations by Ragin (2006, 2008), the consistency threshold for configurations included in the analysis was set at 0.80 . The model's goodness of fit is measured on two indices: solution consistency - in other words, the degree to which the observations corresponding to each configuration lead to the respective outcome (parallel to statistical significance), and coverage - in other words, the proportion of cases leading to the outcome that belongs to a configuration (parallel to $\mathrm{R}^{2}$ in regression models) (Fiss, 2007; Ragin, 2006).

\section{Findings}

\subsection{Results from the longitudinal regression analysis}

In this study, the mixed effects model is found to be superior to both fixed effects and random effects models. A comparison of the betweenand within-group $\mathrm{R}^{2} \mathrm{~s}$ obtained from regression on group means $(0.12$ and 0.01 , respectively) suggests that our set of variables (i.e., the distinct MO dimensions, together with the contextual variables business cycle,

Table 4

Parameter estimates for the mixed effects models.

\begin{tabular}{|c|c|c|c|c|}
\hline \multirow[t]{2}{*}{ Variable } & \multicolumn{2}{|l|}{$\begin{array}{l}\text { Mixed effects } \\
\text { model }\end{array}$} & \multicolumn{2}{|c|}{$\begin{array}{l}\text { Mixed effects model } \\
\text { with industry dummies }\end{array}$} \\
\hline & Parameter & SD & Parameter & SD \\
\hline Customer orientation & 14.95 & 19.85 & 19.29 & 19.84 \\
\hline Competitor orientation & $-53.33^{* * *}$ & 14.20 & $-63.19^{* * *}$ & 14.12 \\
\hline Interfunctional coordination & $39.30^{* *}$ & 16.91 & $42.20^{* *}$ & 17.09 \\
\hline Number of employees & 4.71 & 5.83 & 4.79 & 5.69 \\
\hline Intercept & -28.35 & 79.33 & -18.37 & 80.31 \\
\hline Manufacturing & - & - & 0.98 & 32.44 \\
\hline Information and communication & - & - & $68.15^{*}$ & 39.44 \\
\hline $\begin{array}{l}\text { Professional, scientific, } \\
\text { and technical activities }\end{array}$ & - & - & -48.20 & 39.05 \\
\hline Wholesale and retail trade & - & - & -13.42 & 38.92 \\
\hline
\end{tabular}

$* \mathrm{p}<0.10$

** $\mathrm{p}<0.05$

$* * * \mathrm{p}<0.01$ 
industry sector, and firm size) explains roughly $12 \%$ of the performance variation. The results of the panel data analysis for the general mixed effects model are presented in Table 4 (columns 1 and 2).

The findings presented in Table 4 suggest that, when moving from an economic upturn to a downturn, the performance effect of interfunctional coordination strengthens (in support of $\mathrm{H} 3$ ), the performance implications of competitor orientation decline (contrary to $\mathrm{H} 2$ ), and the impact of customer orientation on firm performance remains statistically the same (not supporting $\mathrm{H} 1$ ).

Continuing with the mixed effects modeling approach, we added dummy variables for the four leading industry sectors to incorporate industry specificity in our analysis. The results from this analysis are presented in Table 4 (columns 3 and 4). Our findings further highlight the increasing but split roles of competitor orientation and interfunctional coordination in contributing to firm performance, as the coefficients are even higher than for the general model. This increase in the regression coefficients further confirms the differing reactions to the tightening economic environment across different industries. However, out of the four industry sectors included in our analysis, the performance effect is significant only for the Information and communication sector, which is found to cope better than the others with the declining economy. Thus, firms in the Information and communication sector overall appear to be particularly well able to respond to the challenges of the business cycle.

\subsection{Results from the fuzzy set Qualitative Comparative Analysis}

The subsequent configurational analysis allows us to study further the industry-specific combinations of MO, effective under different economic conditions. The high-performing configurations identified in the fsQCA are reported in Table 5.

Five distinct configurations, each consistently associated with high firm performance, are identified, covering roughly $11 \%$ of the variance in performance. Somewhat expectedly, the only configuration applicable to both phases of the business cycle is characterized by strong customer orientation, strong competitor orientation, and strong interfunctional coordination. Surprisingly, all high-performing configurations identified relate to firms operating in either Information and communications or Professional, scientific, and technical activities. For Manufacturing and Wholesale and retail trade, also included in the analysis, no highperforming configurations are identified overall.

Table 5

Configurations of $\mathrm{MO}$ associated with high firm performance.

\begin{tabular}{|c|c|c|c|c|c|}
\hline \multirow[t]{2}{*}{ Configuration } & \multicolumn{5}{|l|}{ Solution } \\
\hline & 1 & 2 & 3 & 4 & 5 \\
\hline \multicolumn{6}{|l|}{ Market orientation $^{\mathrm{a}}$} \\
\hline Customer orientation & $\bullet$ & $\bullet$ & - & & $\bullet$ \\
\hline Competitor orientation & & $\bullet$ & $\otimes$ & $\bullet$ & $\bullet$ \\
\hline $\begin{array}{l}\text { Interfunctional } \\
\text { coordination }\end{array}$ & $\otimes$ & $\bullet$ & - & $\bullet$ & $\bullet$ \\
\hline \multicolumn{6}{|l|}{ Context } \\
\hline $\begin{array}{l}\text { Economic } \\
\text { environment }\end{array}$ & Downturn & Downturn & Downturn & Downturn & \\
\hline Industry sector ${ }^{\mathrm{b}}$ & $\mathrm{M}$ & $\mathrm{M}$ & $\mathrm{J}$ & $\mathrm{J}$ & $\mathrm{J}$ \\
\hline Firm size & Small & Large & Small & Large & Large \\
\hline \multicolumn{6}{|l|}{ Goodness of fit } \\
\hline Raw coverage & 0.03 & 0.02 & 0.02 & 0.02 & 0.05 \\
\hline Unique coverage & 0.02 & 0.02 & 0.02 & 0.00 & 0.02 \\
\hline Consistency & 0.84 & 0.80 & 0.86 & 0.83 & 0.82 \\
\hline Solution coverage & 0.11 & & & & \\
\hline Solution consistency & 0.83 & & & & \\
\hline
\end{tabular}

a $\bullet$ indicates the presence of a condition, $\otimes$ indicates its absence. Blank space indicates "don't care."

b C denotes Manufacturing, G Wholesale and retail trade, J Information and communication, and M Professional, scientific, and technical activities.
For firms operating in Professional, scientific, and technical activities two high-performing configurations of MO are identified: one characterized by a "full" MO, incorporating customer orientation, competitor orientation, and interfunctional coordination applicable to large firms; the other characterized by strong customer orientation and, somewhat surprisingly, a lack of interfunctional coordination. As the latter configuration relates to small firms only, this might be explained by the firms' size - in small firms, no formal coordination across different functions or departments is needed, as the organization overall may be less formally structured.

For firms operating in the Information and communication sector, three distinct configurations associated with high firm performance are identified, two applicable to large firms, and one to small firms. The two configurations for large firms are both characterized by strong interfunctional coordination and competitor orientation, the sole difference stemming from the presence of customer orientation. The configuration characterized by a "full" MO is applicable to both an economic upturn and a downturn, whereas in the other, customer orientation is not necessary for producing high performance during a downturn. The configuration identified for small firms operating in this industry sector is characterized by strong customer orientation and interfunctional coordination, but a weak competitor orientation.

A strong customer orientation is required in all high-performing configurations, except for the one applicable to large firms in the Information and communication sector during a downturn, which is characterized by a strong competitor orientation and interfunctional coordination. Moreover, in none of the configurations for small firms is competitor orientation required to achieve high performance. This implies that for a small firm to survive, a strong focus on own business and customers is required, whereas overly concentrating on others may even be detrimental. On the contrary, within the configurations identified, for all large firms regardless of their industry sector, competitor orientation combined with interfunctional coordination is required to achieve performance gains.

\section{Discussion and conclusions}

\subsection{Summary of findings}

The results from our regression analyses, in line with our theorybased assumption, emphasize the growing importance of interfunctional coordination in a declining economy. However, the results for competitor orientation are contrary to what was expected. The diminishing performance effect from an upturn to a downturn is surprising; given that competition under such conditions is often very intense, we expected that a strong competitor orientation would lead to better performance during a downturn (Noble et al., 2002; Theodosiou, Kehagias, \& Katsikea, 2012). The performance impact of customer orientation, in turn, remains unaltered between the two times of measurement. This finding, too, is somewhat surprising, as we expected the effectiveness of customer orientation to be stronger during an economic upturn. The result can, however, at least be partly explained by a relatively high level of customer orientation developed by the firms in our sample, turning customer orientation from a source of competitive advantage into a "cost of competing" (cf. Kumar et al., 2011).

In the subsequent fsQCA, all but one high-performing configurations identified relate to the economic downturn only. This finding further suggests that during an upturn, MO is no longer a feasible source of competitive advantage (Kumar et al., 2011). Interestingly, a strong customer orientation is present in all but one high-performing configurations, further supporting our regression findings. It is also notable that all the identified configurations relate to firms operating in either the Information and communications sector or Professional, scientific, and technical activities. This might stem from MO generally playing a stronger role in B-to-B services, compared to industrial goods or even consumer services (De Brentani \& Ragot, 1996), and therefore reflect a 
more general development of $\mathrm{MO}$ in different industries. Thus, the role of $\mathrm{MO}$ as a source of competitive advantage versus a mere cost of competing, based on our findings, appears to be industry-specific.

\subsection{Theoretical and methodological contributions}

This study contributes to the literature on MO and its performance outcomes during the different phases of the business cycle in six main respects. First, although prior studies suggest the business cycle and its firm performance implications have a remarkable influence on B-to-B firms' marketing (e.g., Rollins et al., 2014), and vice versa (e.g., Deleersnyder et al., 2004; Srinivasan et al., 2005), empirical studies on the topic remain scarce. We extend the current understanding of the topic by examining how the role and impact of MO and its different forms vary across the business cycle.

More specifically, the findings of the present study point to the changing managerial challenges between an economic upturn and a downturn. While gaining superior performance from mere MO during an upturn can be difficult (cf. Kumar et al., 2011), during a downturn strong interfunctional coordination may serve as an effective shelter against fast changes in the marketplace calling for strategic agility (Doz \& Kosonen, 2010). The changing role of MO and its dimensions in creating competitive advantage is also reflected in the only "path" to high performance that remains consistent, regardless of economic fluctuation, consisting of a "full" MO. Our findings thus suggest that the most effective - though not necessarily the most efficient approach to MO across the business cycle would be to develop all its distinct dimensions simultaneously.

Second, our findings also suggest that the performance effects and relative role of the MO dimensions vary across different economic conditions. Specifically, when moving from an economic upturn to a downturn, the role of interfunctional coordination increases significantly, whereas the impact of competitor orientation may, on average, even turn negative. This finding empirically supports prior studies (e.g., Noble et al., 2002; Smirnova et al., 2011; Zhou, Brown, Dev, \& Agarwal, 2007), suggesting that disaggregated MO constructs should be used. Thus, in order to gain a comprehensive perspective of the performance outcomes of MO, its distinct dimensions - often reflecting distinct strategic foci - should be considered separately. This would help overcome the aggregation bias presumably present in many extant studies in the field (cf. Grewal, Chandrashekaran, Johnson, \& Mallapragada, 2013).

Third, building on previous studies recognizing the different forms of MO adopted by individual firms (e.g., Balakrishnan, 1996; Dobni \& Luffman, 2000; Greenley, 1995), our empirical findings from the configurational analysis provide support for contingency arguments claiming that companies should match their MO to their business environments (Zeithaml, Varadarajan, \& Zeithaml, 1988; Zhou et al., 2007). In this study, we further elaborate on the notion of contingency by introducing a number of high-performing configurations, in other words, constellations of MO dimensions together with environmental factors that combined lead to high performance outcomes (Meyer, Tsui, \& Hinings, 1993). Thus, our findings provide a more detailed understanding of the individual configurations or "recipes" associated with high firm performance in individual B-to-B firms.

Fourth, in addition to capturing differences over the business cycle, our findings shed light on the varying roles of MO across industry sectors. Interestingly, the only industries included in our analysis that truly benefit from MO are the Information and communications industry and the Professional, scientific, and technical activities industry, both of which focus heavily on B-to-B services. The result is in line with the meta-analytical findings of Cano, Carrillat, and Jaramillo (2004), who conclude that the performance outcomes of MO in service firms are higher than those in their manufacturing counterparts. Furthermore, several effective forms of MO are found within the industry sectors. This indicates that whether and how developing a strong MO benefits a particular firm depends on both the economic context and the firm's specific industry and target market.

Finally, our study extends the methodological approaches previously adopted in MO studies by introducing two novel perspectives. First, this work is one of the first empirical studies that examine the performance outcomes of MO by adopting a longitudinal approach (notable exceptions are provided by Kumar et al., 2011; Noble et al., 2002). This adds valuable insight to the current understanding of the MO-performance relationship, since $\mathrm{MO}$ as an organizational culture reflects a relatively stable, long-term aspect of the firm that does not necessarily lead to short-term pay-offs (Naidoo, 2010; Narver \& Slater, 1990). Our study's findings, which highlight the changing role of MO and its distinct dimensions over time, underline a more general need to focus on the longitudinal aspects of strategic marketing phenomena.

As a second methodological contribution, to the authors' best knowledge, this is the first study to introduce the configurational approach via the fsQCA to the study of MO and its different forms. This new approach overcomes many of the limitations associated with the more traditional methods of analysis (e.g., the regression analysis used in the present study; see Fiss, 2007), thus providing a valuable addition to the methodological selection in marketing research. In the present study, the use of fsQCA extends the understanding of the aggregate impact of MO to a more specific, configuration-level impact, allowing for higher-order interactions and equifinality. The findings of the present study strongly suggest that the complex causalities involved should be considered when studying strategic marketing concepts.

\subsection{Managerial implications}

From a managerial perspective, this study shows how the distinct MO dimensions, both individually and in combination, yield diverse performance effects in varying economic environments. For a firm to excel throughout economic fluctuations, our findings suggest that a fully market-oriented culture, one that reflects all three dimensions equally, is needed. This is despite recent findings that in some isolated contexts, one of the MO dimensions would be more efficient in terms of improving performance than the others (De Luca et al., 2010; Noble et al., 2002).

However, as highlighted by our findings, extensive competitor orientation may also turn harmful. This holds true especially for contexts characterized by a declining economy, where fierce competition may easily distract the focus from concentrating on developing the own business and customer base. Sheltering from the negative performance impacts of economic fluctuation thus requires the firm to exercise strategic flexibility to best employ its $\mathrm{MO}$ in the changing economic landscape (cf. Grewal \& Tansuhaj, 2001). Our findings suggest that during an economic downturn, this is best achieved by high interfunctional coordination, which enables all departments and functions to act "in concert".

Second, the sensitivity of the performance implications of economic fluctuation to the distinct MO dimensions is found to vary across industry sectors. More specifically, firms focused on industrial services are found to benefit from MO the most, compared to firms in the retail industry, which represents a classical consumer-focused service industry, or manufacturing firms that sell industrial goods. Furthermore, the role of $\mathrm{MO}$ in securing performance during tough economic times is emphasized. However, even for these industries, different high-performing configurations of MO are available. The configurations presented in this study provide benchmarks for B-to-B service firms for better allocations of investments in developing their MO.

In summary, it appears that even for firms operating in the traditional cornerstones of the industrially oriented Finnish economy, the specific "recipes" for building an effective MO vary considerably. This may help explain why previous studies have failed to establish a clear link between aggregate-level MO and performance in "engineering 
countries," such as Finland, Austria, and Germany (Jaakkola et al., 2010). Thus, the present study suggests that there are no silver bullets for developing a MO, but a firm's success in relating with its markets depends on the dynamic firm- and industry-specific environments.

\subsection{Limitations and future research}

In this study, we have explored the impact of MO in Finnish B-to-B markets, across the business cycle marked by the recent great financial crisis. Naturally, like every study, ours is not without limitations. First, we must acknowledge that the specific circumstances of each downturn and recession vary significantly (Mattsson, 2009). Also, although many studies have proposed a proactive approach to responding to recessions, Srinivasan et al. (2005) suggest that firms should respond to downturns in a proactive manner only if they embody an entrepreneurial culture, possess slack resources, and have the flexibility to redeploy these resources. Thus, implementing the findings of the present study into practice requires careful consideration.

This study focuses on the short-term impact of MO and the business cycle on firm performance, relying on ROI as the performance measure. However, both the MO and economic fluctuation may also have implications that will show only in the long run, and could, therefore, be better captured by other performance measures, such as return on assets (ROA). Future studies using autoregressive models (ARM) are encouraged to further investigate this impact. Time series models would also facilitate capturing the impact of changing sentiments along the business cycle, and subsequent increases or reductions in firms' investments in building their assets. A time series approach would also better capture the possible impact of the direction of change in the business cycle (i.e., the shift from upturn to downturn vs. a shift from downturn to upturn), which has been left out of the scope of the present study using panel data.

Provided that this national-level analysis identifies differences in the effective forms of MO across industries, more detailed industry-specific studies are also encouraged. Given the nature of the data used, the present study provides only an overview of the most important industries in a single country. On the one hand, partly due to the small size of the overall focal market, the number of observations included in each industry-specific sample remains limited - therefore, future studies focusing on single-industry settings with larger- $n$ datasets are encouraged to better capture the specificities of each of these industryspecific markets. On the other hand, given the recent suggestions of MO representing the mere cost of competing (Kumar et al., 2011), studies focusing not only on individual industries but also on other national contexts could provide further interesting insight to the topic.

Finally, our findings suggest that the common practice of treating MO as an aggregate, linear-additive concept might, in fact, be somewhat misleading (Grewal et al., 2013). Therefore, future studies should always take into account the multidimensional nature of MO by treating it as a disaggregated construct and examining the implications of each dimension separately.

\section{Acknowledgments}

The data for this study was collected as a part of the StratMark research project funded by the Finnish Funding Agency for Technology and Innovation (Tekes). The authors thank Dr. Ashish Kumar for his valuable suggestions at the early stages of data analysis.

\section{References}

Alajoutsijärvi, K., Klint, M.B., \& Tikkanen, H. (2001). Customer relationship strategies and the smoothing of industry-specific business cycles: The case of the global fine paper industry. Industrial Marketing Management, 30(6), 487-497.

Andersson, P., \& Mattsson, L. -G. (2010). Temporality of resource adjustments in business networks during severe economic recession. Industrial Marketing Management, 39(6), 917-924.
Armstrong, J.S., \& Overton, T.S. (1977). Estimating non-response bias in mail surveys. Journal of Marketing Research, 14(3), 396-402.

Asplund, R., \& Maliranta, M. (2006). Productivity growth: The role of human capital and technology. In J. Ojala, J. Eloranta, \& J. Jalava (Eds.), The road to prosperity - An economic history of Finland (pp. 263-283). Helsinki: Finnish Literature Society.

Balakrishnan, S. (1996). Benefits of customer and competitive orientations in industrial markets. Industrial Marketing Management, 25(4), 257-269.

Barnett, W.P., Greve, H.R., \& Park, D.Y. (1994). An evolutionary model of organizational performance. Strategic Management Journal, 15(8), 11-28.

Cano, C.R., Carrillat, F.A., \& Jaramillo, F. (2004). A meta-analysis of the relationship between market orientation and business performance: Evidence from five continents. International Journal of Research in Marketing, 21(2), 179-200.

Chen, M. -J., Su, K. -H., \& Tsai, W. (2007). Competitive tension: The awareness-motivationcapability perspective. Academy of Management Journal, 50(1), 101-118.

Christensen, C.M., \& Bower, J.L. (1996). Customer power, strategic investment, and the failure of leading firms. Strategic Management Journal, 17(3), 197-218.

De Brentani, U., \& Ragot, E. (1996). Developing new business-to-business professional services: What factors impact performance? Industrial Marketing Management, 25(6), 517-530.

De Luca, L.M., Verona, G., \& Vicari, S. (2010). Market orientation and R\&D effectiveness in high-technology firms: An empirical investigation in the biotechnology industry. Journal of Product Innovation Management, 27(3), 299-320.

Deleersnyder, B., Dekimpe, M.G., Sarvary, M., \& Parker, P.M. (2004). Weathering tight economic times: The sales evolution of consumer durables over the business cycle. Quantitative Marketing and Economics, 2(4), 347-383.

Deleersnyder, B., Dekimpe, M.G., Steenkamp, J.E.M., \& Leeflang, P.S.H. (2009). The role of national culture in advertising's sensitivity to business cycles: An investigation across continents. Journal of Marketing Research, 46(5), 623-636.

Deshpandé, R., Farley, J.U., \& Webster, F.E., Jr. (1993). Corporate culture, customer orientation, and innovativeness in Japanese firms: A quadrad analysis. Journal of Marketing, 57(1), 23-37.

Dobni, C.B., \& Luffman, G. (2000). Implementing marketing strategy through a market orientation. Journal of Marketing Management, 16(8), 895-916.

Doty, D.H., Glick, W.H., \& Huber, G.P. (1993). Fit, equifinality, and organizational effectiveness: A test of two configurational theories. The Academy of Management Journal, 36(6), 1196-1250.

Doz, Y., \& Kosonen, M. (2010). Embedding strategic agility: A leadership agenda for accelerating business model renewal. Long Range Planning, 43(2-3), 370-382.

Eisenhardt, K.M., \& Martin, J.A. (2000). Dynamic capabilities: What are they? Strategic Management Journal, 21(10-11), 1105-1121.

Fiss, P.C. (2007). A set-theoretic approach to organizational configurations. Academy of Management Review, 32(4), 1180-1198.

Frambach, R.T., Fiss, P.C. \& Ingenbleek, P.T.M. (2010). When does customer orientation pay off? A configurational analysis of the performance effects of orientations strategies, and market conditions. Proceedings of the Organization Science Winter Conference XVI.

Gordon, B., Goldfarb, A., \& Yang, L. (2013). Does price elasticity vary with economic growth? A cross-category analysis. Journal of Marketing Research, 50(1), 4-23.

Greenley, G.E. (1995). Forms of market orientation in UK companies. Journal of Management Studies, 32(1), 47-66.

Grewal, R., Chandrashekaran, M., Johnson, J.L., \& Mallapragada, G. (2013). Environments, unobserved heterogeneity, and the effect of market orientation on outcomes for high-tech firms. Journal of the Academy of Marketing Science, 41(2), 206-233.

Grewal, R., \& Tansuhaj, P. (2001). Building organizational capabilities for managing economic crisis: The role of market orientation and strategic flexibility. Journal of Marketing, 65(2), 67-80.

Grinstein, A. (2008). The effect of market orientation and its components on innovation consequences: A meta-analysis. Journal of the Academy of Marketing Science, 36(2), $166-173$.

Grönroos, C. (1994). From marketing mix to relationship marketing - Towards a paradigm shift in marketing. Management Decision, 35(4), 322-339.

Hjerppe, R., \& Jalava, J. (2006). Economic growth and structural change: A century and a half of catching-up. In J. Ojala, J. Eloranta, \& J. Jalava (Eds.), The road to prosperity - An economic history of Finland (pp. 33-63). Helsinki: Finnish Literature Society.

Horn, J.L., \& McArdle, J.J. (1992). A practical and theoretical guide to measurement invariance in aging research. Experimental Aging Research: An International Journal Devoted to the Scientific Study of the Aging Process, 18(3), 117-144.

Hult, G.T.M., \& Ketchen, D.J., Jr. (2001). Does market orientation matter? A test of the relationship between positional advantage and performance. Strategic Management Journal, 22(9), 899-906.

Im, S., \& Workman, J.P. (2004). Market orientation, creativity, and new product performance in high-technology firms. Journal of Marketing, 68(2), 114-132.

Jaakkola, M., Möller, K., Parvinen, P., Evanschitzky, H., \& Mühlbacher, H. (2010). Strategic marketing and business performance: A study in three European 'engineering countries'. Industrial Marketing Management, 39(8), 1300-1310.

Jaworski, B.J., \& Kohli, A.K. (1993). Market orientation: Antecedents and consequences. Journal of Marketing, 57(3), 53-71.

Jöreskog, K.G., \& Sörbom, D. (1993). LISREL 8: Structural equation modeling with the SIMPLIS command language. Scientific Software International.

Kirca, A.H., Jayachandran, S., \& Bearden, W.O. (2005). Market orientation: A meta-analytic review and assessment of its antecedents and impact on performance. Journal of Marketing, 69(2), 24-41.

Kumar, V., Jones, E., Venkatesan, R., \& Leone, R.P. (2011). Is market orientation a source of sustainable competitive advantage or simply the cost of competing? Journal of Marketing, 75(1), 16-30. 
Lai, C. -S., Pai, D. -C., Yang, C. -F., \& Lin, H. -J. (2009). The effects of market orientation on relationship learning and relationship performance in industrial marketing: The dyadic perspectives. Industrial Marketing Management, 38(2), 166-172.

Lance, C.E., Butts, M.M., \& Michels, L.C. (2006). The sources of four commonly reported cutoff criteria - What did they really say? Organizational Research Methods, 9(2), 202-220.

Liao, S.H., Chang, W.J., Wu, C.C., \& Katrichis, J.M. (2011). A survey of market orientation research (1995-2008). Industrial Marketing Management, 40(2), 301-310.

MacCallum, R.C., Browne, M.W., \& Sugawara, H.M. (1996). Power analysis and determination of sample size for covariance structure modeling. Psychological Methods, 1(2), 130-149.

Mattsson, L.G. (2009). Market orientation and resource adjustments during economic recession - A business network perspective. Journal of Customer Behavior, 8(2), $153-162$.

Meyer, A.D., Tsui, A.S., \& Hinings, C.R. (1993). Configurational approaches to organizational analysis. Academy of Management Journal, 36(6), 1175-1195.

Naidoo, V. (2010). Firm survival through a crisis: The influence of market orientation, marketing innovation and business strategy. Industrial Marketing Management, 39(8), 1311-1320.

Narver, J.C., \& Slater, S.F. (1990). The effect of a market orientation on business profitability. Journal of Marketing, 54(4), 20-35.

Narver, J.C., Slater, S.F., \& MacLachlan, D.L. (2004). Responsive and proactive market orientation and new-product success. Journal of Product Innovation Management, 21(5), 334-347.

Nilsson, L., Johnson, M.D., \& Gustafsson, A. (2001). The impact of quality practices on customer satisfaction and business results: Product versus service organizations. Journal of Quality Management, 6(1), 5-27.

Noble, C.H., Sinha, R.K., \& Kumar, A. (2002). Market orientation and alternative strategic orientations: A longitudinal assessment of performance implications. Journal of Marketing, 66(4), 25-39.

Pearce, J.A., II, \& Michael, S.C. (1997). Marketing strategies that make entrepreneurial firms recession-resistant. Journal of Business Venturing, 12(4), 301-314.

Pearce, J.A., II, \& Michael, S.C. (2006). Strategies to prevent economic recessions from causing business failure. Business Horizons, 49(3), 201-209.

Podsakoff, P.M., \& Organ, D.W. (1986). Self-reports in organizational research: Problems and prospects. Journal of Management, 12(4), 531-544.

Porter, M.E. (1980). Competitive strategy: Techniques for analyzing industries and competitors. New York, NY: Free Press.

Powell, T. (1996). How much does industry matter? An alternative empirical test. Strategic Management Journal, 17(4), 323-334.

Quelch, J.A., \& Jocz, K.E. (2009). How to market in a downturn. Harvard Business Review, $87(4), 52-62$.

Ragin, C.C. (2006). Set relations in social research: Evaluating their consistency and coverage. Political Analysis, 14(3), 291-310.

Ragin, C.C. (2008). Redesigning social inquiry: Fuzzy sets and beyond. Chicago, IL: University of Chicago Press.

Roberts, K. (2003). What strategic investments should you make during a recession to gain competitive advantage in the recovery? Strategy E' Leadership, 31(4), 31-39.
Rock, D.A., Werts, C.E., \& Flaugher, R.L. (1978). The use of analysis of covariance structures for comparing the psychometric properties of multiple variables across populations. Multivariate Behavioral Research, 13(4), 403-418.

Rollins, M., Nickell, D., \& Ennis, J. (2014). The impact of economic downturns on marketing. Journal of Business Research, 67(1), 2727-2731.

Ruekert, R.W., \& Walker, O.C., Jr. (1987). Marketing's interaction with other functional units: A conceptual framework and empirical evidence. Journal of Marketing, 51(1), $1-19$.

Rust, R.T., \& Zahorik, A.J. (1993). Customer satisfaction, customer retention, and market share. Journal of Retailing, 69(2), 193-215.

Slater, S.F., \& Narver, J.C. (1994). Does competitive environment moderate the market orientation-performance relationship? Journal of Marketing, 58(1), 46-55.

Smirnova, M., Naudé, P., Henneberg, S.C., Mouzas, S., \& Kouchtch, S.P. (2011). The impact of market orientation on the development of relational capabilities and performance outcomes: The case of Russian industrial firms. Industrial Marketing Management, 40(1), 44-53.

Srinivasan, R., Lilien, G.L., \& Sridhar, S. (2011). Should firms spend more on research and development and advertising during recessions? Journal of Marketing, 75(3), 49-65.

Srinivasan, R., Rangaswamy, A., \& Lilien, G.L. (2005). Turning adversity into advantage: Does proactive marketing during a recession pay off? International Journal of Research in Marketing, 22(2), 109-125.

Steenkamp, J.E.M., \& Baumgartner, H. (1998). Assessing measurement invariance in cross-national consumer research. Journal of Consumer Research, 25(1), 78-90.

Steenkamp, J.E.M., \& Fang, E. (2011). The impact of economic contractions on the effectiveness of R\&D and advertising: Evidence from U.S. companies spanning three decades. Marketing Science, 30(4), 628-645.

Theodosiou, M., Kehagias, J., \& Katsikea, E. (2012). Strategic orientations, marketing capabilities and firm performance: An empirical investigation in the context of frontline managers in service organizations. Industrial Marketing Management, 41(7), 1058-1070.

Tuominen, M., Rajala, A., \& Möller, K. (2004). Market-driving versus market-driven: Divergent roles of market orientation in business relationships. Industrial Marketing Management, 33(3), 207-217.

Van Heerde, H., Gijsenberg, M., Dekimpe, M., \& Steenkamp, J. (2013). Price and advertising effectiveness over the business cycle. Journal of Marketing Research, 50(2), 177-193.

Wilkinson, M. (2010). Marketing plays critical role. Charter, 81(3), 24-26.

Zeithaml, V.A., Varadarajan, P., \& Zeithaml, C.P. (1988). The contingency approach: Its foundations and relevance to theory building and research in marketing. European Journal of Marketing, 22(7), 37-64.

Zhou, K.Z., Brown, J.R., \& Dev, C.S. (2009). Market orientation, competitive advantage, and performance: A demand-based perspective. Journal of Business Research, 62(11), 1063-1070.

Zhou, K.Z., Brown, J.R., Dev, C.S., \& Agarwal, S. (2007). The effects of customer and competitor orientations on performance in global markets: A contingency analysis. Journal of International Business Studies, 38(2), 303-319. 